\section{Ultrasound as the new stethoscope: AMSSM pioneers curriculum (gently!)}

\author{
Karim M Khan
}

Five landmark moments in sport and exercise medicine: (1) Bannister's 3:59.4 at Iffley Road; (2) Ron Clarke collapses at the Mexico Olympic Games; (3) Jerry Morris publishes Exercise: today's best buy in public health; (4) the Concussion Consensus Meetings in Vienna, Prague \& Zurich; (5) the first World Congress on Sports Injury Prevention in Oslo; (6) Keith Richards falls out of a palm tree at the Wakaya Club in Fiji and injures his back during the tour appropriately called 'A Bigger Bang.' 'Hey!!!!, but that's like eight events' says my 16-year-old personality. Be that as it may, it's a highly contrived segue to highlight that office ultrasound for diagnosis and procedures has arrived-ready or not. The office setting for musculoskeletal ultrasound might match medical miracles such as organ transplantation, Charnley hips and the bark of the yohimbe tree. This is not just for the big leagues - the ultrasounds being shared by mums on junior soccer sidelines may be those of flexor tendons, not only fetal chambers.

\section{Five diverse opinions and you decide!}

$B J S M$ carries the world exclusive of this proposed/suggested curriculum (see page 1144) but that is not all. Two live

The University of British Columbia, Vancouver, Canada Correspondence to Dr Karim M Khan, The University of British Columbia, UBC, Centre for Hip Health and Mobility, Suite 320-5950 University Blvd, Vancouver V6T 1Z3, Canada; karim.khan@ubc.ca
Presidents opine (see page 1135), an Olympic radiologist scans the issue (see page 1136), and a physician trained in both sports medicine and radiology sees common ground (see page 1138). Escalating evidence all the way to level 4, James and colleagues (see page 1149) share their experience of postgame, ultrasound-assisted injection. Orchard (see page 1134) sees the day where the traditional stadium vendor's chant of 'chips, lollies and potato cakes' is replaced by the sartorial waiter's mellifluous upsell, 'would you like an MRI with that beer?' Check out the curriculum (see page 1144) and share your thoughts immediately via e-letters. Alternatively, if you eschew the digital age, email me directly (karim. khan@ubc.ca), text, tweet (@BJSM_BMJ) or direct message using Skype. And did I mention that we beat NEJM and JAMA for that curriculum?

\section{New ultrasound method and free podcast!}

Of course we did lose to JAMA earlier in the year when Robert-Jan de Vos and colleagues published their randomised controlled trial (RCT) of platelet-rich plasma (PRP) in 'that journal'. ${ }^{1}$ Our wonderful Dutch colleagues have seen the error in their ways-the ultrasound findings from that RCT grace this issue (see page 1153). No signs of benefit of PRP in the Achilles tendon (see December 2010's issue of BJSM IPHP, page 1071). Note the innovation of having the "ultrasound tissue characterisation'-a novel way of quantifying ultrasound images. An innovation from the thoroughbred racing industry and possibly the next big thing in imaging - this is a 'giant leap' rather than a small step. Listen to de Vos and Adam Weir's podcast about PRP and managing Achilles tendinopathy (http://podcasts. bmj.com/bjsm)

\section{Christmas pudding}

I don't want to be Uncle Scrooge, so I won't flag the coincidence that Duncan Macfarlane's review (see page 1197) is in this issue. Exercise and diet in weight management-what works and what doesn't. Read that keeping in mind Richard Weiler and Steven Blair's BMJ Head to Head-Physical inactivity should dominate over obesity in the public health debate. ${ }^{2}$ Instead, I'll remind you how easy it is to find free stuff (Xmas presents?) on the home page-podcasts (http:// podcasts.bmj.com/bjsm/), blogs (http:// blogs.bmj.com/bjsm/) and videos (http:// www.youtube.com/user/BJSMVideos). And remember a tip a day keeps injury at bay-Twittertips@BJSM_BMJ.3

Acknowledgements Thanks to M Smith for the 'new stethoscope' tag-line - conceived while running together in Kona and the idea all his.

Provenance and peer review Not commissioned; not externally peer reviewed.

Accepted 26 October 2010

Br J Sports Med 2010;44:1133.

doi:10.1136/bjsm.2010.081034

\section{REFERENCES}

1. de Vos RJ, Weir A, van Schie HT, et al. Platelet-rich plasma injection for chronic Achilles tendinopathy: a randomized controlled trial. JAMA 2010;303:144-9.

2. Weiler R, Stamatakis E, Blair S. Should health policy focus on physical activity rather than obesity? Yes. BMJ 2010;340:c2603.

3. Khan KM. The only constant is change: UKSEM, ISEM, Twitter, Podcasts and YouTube reflect the dynamic nature of sport and exercise medicine. Br J Sports Med 2010;44:911. 